\title{
DEVICES OF TEXTUAL ILLUSION: VICTIMIZATION IN ROMANCE SCAM E-LETTERS
}

\author{
GUNTARS DREIJERS \\ Ventspils University of Applied Sciences, Latvia \\ guntarsd@venta.lv

\section{VALDA RUDZIŠA} \\ Ventspils University of Applied Sciences, Latvia \\ valda.rudzisa@venta.lv
}

\begin{abstract}
Virtual communication transcends national boundaries and allows establishing and maintaining contacts efficiently. However, it also poses threats to integrity and ethical online conduct. In particular, dating sites and unsolicited e-messages often prey on vulnerable unsuspecting people with an intention to extort financial means. The internet is a medium where anonymity, disguise and fraud are widespread. Scammers use linguopsychological devices to lure potential victims into the scam scenario. Devices were screened and categorized from seven letter-sets (each set containing 18-23 letters) including correspondence with scammers. The sets revealed similar lexical and macrostructural patterns common in e-romance scam. Frequently employed devices appeared to signal scammers' malicious intents often potentially detrimental to a victim. Persuasion, flattering, appeal to trust, core human drives such as bonding, greed, altruism are among the most popular scammers' devices. The method of structural reduction allowed establishing functional stages in the macrostructure of letter-sets.
\end{abstract}

Keywords: dating sites, e-romance scam, linguopsychological devices, electronic communication

\section{Introduction}

E-romance scammers globally wield patterns of linguopsychological devices to victimize unsuspecting individuals through manipulative communicative acts online. In particular, various global social media sites such as Facebook and Instagram have been used to provide space for the malicious creation of the illusion of meaning and intention with an aim to extort victims' financial assets. The unlawful practice of extortion has been affecting individuals globally notably in the West. 
Communication has many forms, intents and purposes. It is multimodal and represents real and imagined worlds. However, besides the benefit of speed, convenience, borderless and instantaneous exchange of information in a global digitally mediated medium, the problem of online scam has attracted forensic linguists' urgent attention to the so-called 'white-collar' crime.

More recently the FBI has defined 'white-collar' crime (ones with financial motivations) as 'those illegal acts which are characterized by deceit, concealment, or violation of trust and which are not dependent upon the application or threat of physical force or violence. (Luchjenbroers, June and Olsson 2014: 139)

The article focuses, in particular, on a type of online interaction widely known as dating online. The illusory nature of frequent dating chats and e-correspondence have often resulted in frauds or e-romance scam. With more people becoming victims of such online fraud, the issue has been receiving a broad interdisciplinary involvement of specialists from various fields.

The aim of the article is to highlight features of a relatively new online phenomenon-e-scams by identifying language features that jeopardize the victim, create a state of illusion of possible romance, and victimize the target through linguopsychological devices. Upon falling into a trap of illusory trust prepared by scammers, the victim mistranslates the message affectively (hence, linguopsychological aspects of scam as formal linguistic signs trigger behavioral responses and perception). The victim's readiness to trust such correspondence results from her, or his, collaborative input. As it was suggested:

Conversations are different. We change the context in such a way that what the speaker says comes out true. (Cappelen, Herman and Dever 2016: 178)

In search of romance, the victim seldom scrutinizes falsehood embedded in the message. In addition, affective priming is a powerful strategy to maintain trust:

Affective priming research seems to lead us to two related conclusions: (1) that slight exposure is significant in that it influences our evaluations; and (2) that repetitive exposure to stimuli presented as emotionally significant enhances the likelihood of our slanting towards the emotion being sought, for whatever reason. (Janicki 2015: 68)

Latvian and English articles in online media suggest the scope of fraud: Uzmanies, skameri! (Beware scammers!); Sievietes alkst uzmanības, krāpnieki naudas. Tā iespējams šķirties no milzu summām. (Women Crave for Attention, Scammers - for Money. Thus, It Is Possible to Part from Enormous Savings); Pieredze ar "scammers" jeb viltus valdzinātājiem - krāpniekiem (Experience with "Scammers" or Fake Charmers - Fraudsters); Afrikas skameri - mīlestības no pirmā acu skatiena (African Scammers - Love at First Sight); Krāpšana 
starptautiskajos iepazī̌anās portālos (Scam in International Dating Sites); Sludinājumu krāpnieki no Nigērijas (Classifieds Scammers from Nigeria). English news websites have similar headlines taking the form of acts of warning: Beware of Romance scammers Looking for More Than Love; Watch out for 'Online' Romance Scams, BBB Warns; Beware of Online Romance Scams, Ohio attorney General Warns. Although several websites (romancescam.org, scamsoftheheart.blogspot.com, FBI's homepage "Scams and Safety" fbi.gov/scams-and-safety, scamwatch.gov.au, bbb-study-online-romance-scamsstudy.pdf, etc.) warn about the consequences of online fraud, there are few foci on the language design patterns. Research on scammers traditionally focuses on the issues detrimental mental consequences for the victims (and also for scammers), and on prevention typical of the field of victimology that covers aspects of effects, prevalence, and the scam process per se. However, with the developments in forensic linguistics methodology, it is possible to discern scammers' pragmatic implications on both microlinguistic (i.e. mainly lexical) and macrostructural (i.e. textual) levels. The scammers' focus on set lexical items and patterns of structuring scam adjusted to the psychological profile of the victim may leave traces of linguistically analyzable regularities common in online dating e-scam. Effective scamming, therefore, consists of elaborate linguistic and psychological devices; they are structured so as to maximize the victimization of potential daters. However, the awareness of linguopsychological devices can be an asset in the prevention of successful for the actors, and detrimental for the victims scam scenarios. Numerous warning titles suggest that the rapid development of information and communication technologies offers alternatives for often less successful real life romance. Anonymity in the digital environment allows daters to experience more freedom, and also higher risk (Rege 2009: 494). However, anonymity does not shield against incidental or deliberate disclosure of private data, which can turn into unsafe practice with unforeseen consequences (Deumert $2014: 30$ ).

\section{Methodology}

For the present study seven letter-sets have been analysed. Each set consisted of 18 to 23 letters. Two of the sets were mock ones with the authors of the article agreeing to engage willingly in an e-scam correspondence. The initiative was on the scammers' part who identified themselves with fake online profiles. The objectives, for that reason, were to identify means of creating the illusion of trust leading to a plea for money, and to establish a textual pattern of a letter set through the method of structural reduction that helped identifying functional stages necessary in building online trust. After studying sample letter-sets on the website romancescam.org, the authors agreed to respond to scammers' unsolicited messages on Facebook. The overall scammers' linguopsychological approach 
matched the patterns in sample letters available online. The method of structural reduction allowed us to establish macrostructural and microlinguistic structures, elements in letter-sets (e.g., the organization of communication, linguistic devices, patterns of address and letter closings in each set). The AntConc tool determined the high frequency lexeme distribution across the plot of the sets. Thus, generalizations about establishing an illusion of online trust were made. When scammers' plea for money came, the authors identified themselves as researchers of linguistic devices in correspondence with scammers. The analysis was based on the linguistic material (i.e., content, formal text properties) of e-scam lettersets, which provided main data for the conclusions.

\section{Scam - Illusion Trap}

The term 'illusion' is used mainly in the scientific discourse of psychology, and it suggests a stimulus or experience generated as misleading and deceptive (Coleman 2001: 354). Illusion is typically connected with deception (in the case of e-romance scam, intended by a sender of the message) - "a message knowingly transmitted by a sender to foster a false belief or conclusion by the received" (Whitty, Monica and Young 2017: 128; also Tatar 2018: 69). In digital deception, "the intentional control of information in a technologically mediated message creates a false belief in the receiver of the message" by typically creating an identity or message deception" (Whitty, Monica and Young 2017: 129-130). Scammers operate at two levels - they falsify the message by presenting an illusory and promissory future of establishing an emotional bond between the victim and the scammer, and they falsify the identity they present online because "comprehension and interpretation too are shaped and frequently driven by the perception of identity" (Joseph 2004: 224). Characteristically, they choose potential victims beyond the age of 50, divorced, in search of relationship and who are self-made people. Formally, devices of illusion leave a stylistic fingerprint. Because scamming may result in a message recipient's financial losses, the illusion that does not turn into a desirable outcome for the receiver is referred to as the convenient illusion and "it is reflected in psychological pain" (Smail 2015: VIII). It happens because the linguistic and psychological output on the part of the victim does not satisfy the victim's own expectations. The title of an online article states - "Romance Scams Lead to Broken Hearts, Empty Bank Accounts" (RSCAMS). In this approach, the illusion caused by linguopsychological devices is both convenient (to sustain hope, namely, illusion) and emotionally detrimental in the end. Despite the fact that about 73 per cent of individuals, according to Whitty and Young, believe deception is a widespread phenomenon online (Whitty, Monica and Young 2017: 133), people fall into the illusory trap of scammer's exercise of linguistic and psychological asymmetrical (i.e., unequal) power relations. A non-veridical experience which "fails to either accurately resemble 
reality, or has no corresponding object in reality" (Locatelli, Roberta and Wilson 2017: 199) stems from the interplay of sustained, regular, even predictable use of linguopsychological devices.

\section{Scope and Dimensions of Romance Scams}

Essentially, online scams have four dimensions. The most prominent is the linguistic one. Scammers' scenarios in the letter-sets have a certain macrostructure (analysed hereinafter with the method of structural reduction), and microlinguistic elements (e.g., forms of address, letter closings).

In a legal dimension, scamming is recognized globally with a reference to the Nigerian Criminal Code Section 419 that mentions the offence of obtaining property of another by false pretences. Other international documents mention online crime, e.g. Convention on Cybercrime of the Council of Europe adopted in 2001. In Latvia, cybercrime is recognized in the Criminal Law Article 177. Financially, according to the FBI, losses to romance scam may average to more than USD 10,430 per victim (ONLINE R-SCAMS).

The linguistic dimension is closely tied to various psychological mechanisms explaining the creation of illusion through the textual material. For instance, the illusion of control suggests that the victim has a control over events (Colman 2001: 355). The social compensation hypothesis states that those individuals high in dating or social anxiety and low in social competence will use online dating (Whitty, Monica and Young 2017: 41). In other cases, the rich-get-richer hypothesis would argue that people low in social anxiety and high in social competence will be more likely to use online dating (ibid. 41). The social penetration theory states that relationships gradually move to greater levels of intimacy over time with the help of online dating tools (Joinson, Adam and Whitty 2009: 28). Manipulation and victimization are also explained by the feature-based theory, namely, the more synchronous a medium is, the more lying should occur (ibid. 66). For the illusion to work, the elaboration-likelihood model suggests the degree of persuasion and attitude depends upon the probability that people will devote mental effort to elaborate upon the information they receive (Hill 2009: 253). Falling for a scam may be linked to errors in decision-making. Scammers create situations that increase the likelihood of poor decision-making (Whitty, Monica and Young 2017: 150). Psychological trickery complements linguistic devices effectively.

\section{Language of Scam: Microlinguistic Properties}

Scammers' language presents an array of devices that make a promise of the possible (happy) future (Joinson, Adam and Whitty 2009: 83). Direct probing 
questions reduce uncertainty (ibid. 100), e.g. "What do you dream about during the day?"; "Is everything alright with you there?"; "I hope you are having a good day? "; "I trust you had a wonderful weekend, my love?"; "How are you today?" Persuasion, flattering, poetic expressions, forms of address or pet names, an appeal to core human drives (e.g. bonding, acquiring, trusting), attention inducing buzz words, non-native English can be documented in scammers' repertoire.

Prominence is given to pragmatic implications - implicit and explicit. Thus, persuasion is a typical strategy to come to financial terms with a victim. The following example with features of non-standard English calls for a victim's data necessary for eliciting money through either transfers or postal services. The promised rewards for compliance (non-standard English explained in square parenthesis) are usually pecuniary without the actual implementation of the promise - "I have made arrangement [a missing indefinite article 'an'] with a courier agent in the Labuan Island sea port to deliver the package to you, including my business money for safety reasons. Also provide the below details information [incorrect word order] requested to receive the package: your complete name, your receiving address, a direct telephone number to reach you." In another mock e-correspondence, a scammer wrote - "My lovely angel Anete please send [informal e-style with missing punctuation marks] this your data [a superfluous demonstrative pronouns] as follows here 1) your full name, your home address, 3) your mobile phone number, 4) your nearest airport, 5) your city, 6) your country. I was talking with the German traveller agent and I couldn't understand his very well [an incorrect pronoun instead of an object pronoun 'him'], Honey I finally got a new traveller agent from Russian federation [the absence of the definite article and a name of the country without capitalization] who will us prepare [incorrect word order] my travelling documents and he is reliable person [without an indefinite article 'a']. Although it is optional to capitalize or write messages without capital letters in an informal e-letter, such slips as articles and word order are not typical of native speakers. Scammers often present themselves as native English speakers with high standing positions in the United Nations, or NATO, and who are about to retire to settle for a calm life after an intense service in the world's hotspots. The authors also looked into the plot design produced by the AntConc tool considering three typical words used in eromance scam. 
Love:

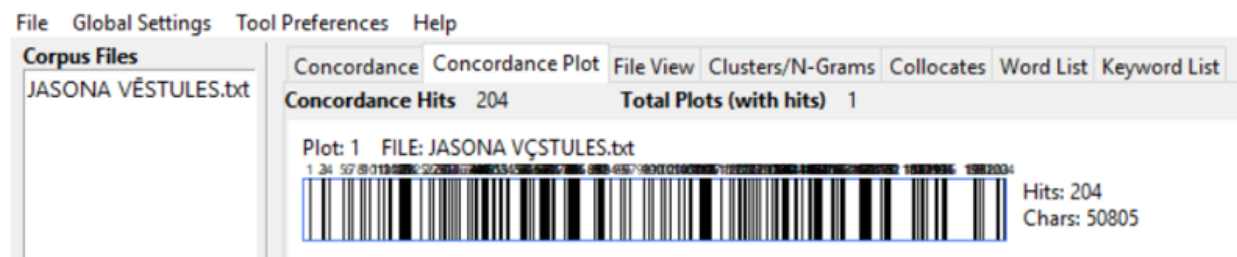

Figure 1. Plot Frequency of 'Love'

In a letter-set, the word 'love' commonly used to address the victim appears for about 204 times. Besides, it occurs at regular intervals dispersed densely across the file processed by AntConc. Among other forms of address, the following ones are popular with scammers - my angel, my sunshine, honey, my dearest..., my love, my dear God's gift, my queen, my beloved..., darling, baby, my dear love and sweet honey, sweetie, my baby queen, my sweetheart, my hope, my pretty woman, my dear lovely and sweetest honey of joy, etc. Forms of address vary in length - from one-word to eight-word forms of address.

Sweet:

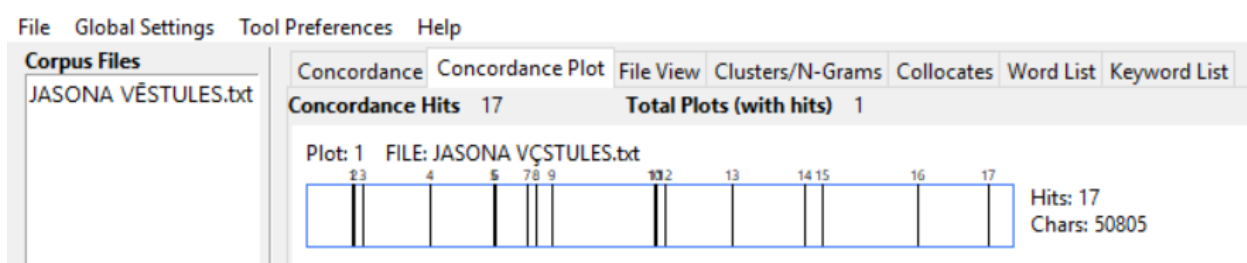

Figure 2. Plot Frequency of 'Sweet'

For the comparison, the word 'sweet', though less frequent, occurs at regular intervals. Both 'love' and 'sweet' add the dimension of deeper intimacy and sustains the illusory trap of amorous correspondence. The pragmatic intention is revealed later in a letter-set.

Money:

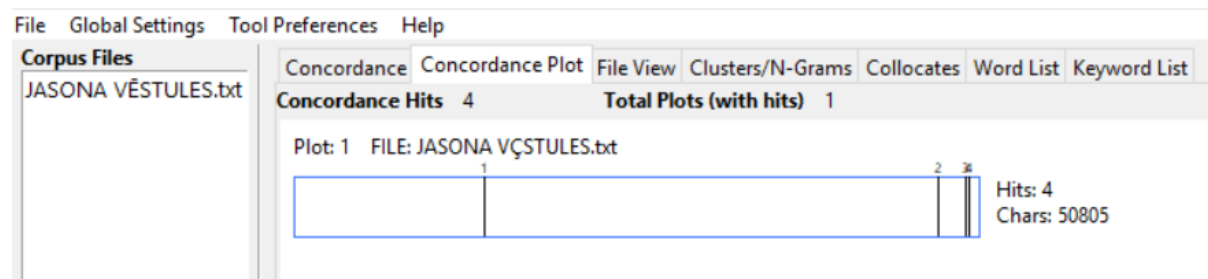

Figure 3. Plot Frequency of 'Money' 
The initial mention of 'money' describes the fictitious well-being of a scammer, and the requests for money appear typically at the end of the romance scam. Repetition is a crucial device in online scam letters. Sequence, regularity, finalization facilitate communication, ensure the flow of the rhythm; they also focus the victim's attention to the possible, imagined future and take the scammer closer to the goal of coming to financial terms. An illusory picture of well-being despite the features of non-standard English creates trust in a scammer's financial situation: "I am stable and independent. I always provide everything for my son that he needs in life to be what he wants to be. Luckily, I have my own fully furnish [the absence of the past participle] 5 bedroom house and two luxurious cars...so life is good."

Flattering is another device used repetitively to keep the victim's attention focused: "My heart accelerates at the speed of light, every time I breathe, I hear the rhythms of your sweet name, so melodious and charming. I love your eyes, your smile, your hair, your body, damn, it drives me off the wall, and I am crazy about you. You complete me, you mean the world to me."

Poetic expressions evoke the sense of intimacy and facilitate bonding: "We are lovers; we're two birds, and we're soul mates. You and I, under the moonlight, together until the stars don't shine any more."

Language of scammers' e-romance correspondence appeals to core human drives, notably, the drive to bond, to defend and to feel - "what matters is true love, understanding, respect, honesty and trust". A volunteer group's homepage "Scams of the Heart" explains the manipulation in behavioural terms - "they mess up sleep patterns, they prey on the person's strengths, they prey on the person's weaknesses, they use social isolation" (SCAMS). Constant online intrusion and verbal reminders aim to establish bonding with the victim.

\footnotetext{
"Patterns in content include similar narratives... and appeals to greed, altruism, trust, and religious feelings. The best defence against them must still entail comprehensive public education about the nature of this scam (and others) and about the telltale characteristics of these letters that signal a con at work." (Schaffer 2012: 157)
}

The premeditated online discourse interferes linguistically with the victim's emotional and behavioural responses. Interestingly, the scammer's text does not follow the principle of the quantity maxim, namely, to contribute as informatively as possible, whereas the victim tends to follow the quantity maxim. In that sense, the pragmatic rule violates the production of a coherent interaction (Coulthard, Malcolm and Johnson 2007: 128). The violation of the quantity maxim is intended to keep the victim's attention to a maximum focus on the message.

Attention inducing buzzwords create an enigmatic aura of romance - "magic, secret, fountain [of relationship], future, hope, sacred". 
Non-native English syntax, spelling and expression might signal suspicion: "You ask me my age?; I am having a meeting with the united nation; I read your email yesterday and I reply you; have a grate day" etc.

Letter closings induce an illusion of yearning, missing, unfulfilled promises: "I embrace you with tenderness; I embrace you with warmth; I embrace you with love and tenderness; I embrace you with the warmth of love; passionately yours forever; kisses, kisses, kisses; your beloved husband; hugs and kisses; hug and sweet kisses; affectionately; with love and happiness always; from your ever handsome man". Microlinguistic properties are similar in all letter-sets.

\section{Language of Scam: Macrostructural Anatomy}

For online scam to attain the goal of obtaining financial assets, e-correspondence is designed in steps or stages. All the stages in letter sets are part of the fully structured scam. With the use of structural reduction, it is possible to establish a well-designed plot where each constituent part has a pragmatic implication "underlying structural patterns highlight the similarities" (Chandler 2002: 92). Each constituent part has a function - "an act...defined from the point of view of its significance for the course of action" (ibid. 92).

As the correspondence between the scammer and the victim develops, the scammer guides the plot and the course of correspondence. As macrostructural constructs, scam letter-sets bear macrostructural semblance. Typical stages involve, first, establishing the initial situation - Thank you very much for agreeing with my suggestion to communicate through our personal email and thanks also for giving me the chance to know more about you. What I'm like? My son would say am the best dad on this planet. My friends say that I am 3 G's Generous, Gregarious and Glamorous! I do my best to attend services Sunday and try to pray every morning and every night before I lay down in bed.

The initial situation may include several functions - enticing the victim to communicate and open up, presenting oneself (i.e. the scammer) as an upright person in a favourable light. The pragmatic implication is to wield trust over the victim.

The next strategic step is to reconnoitre. Reconnaissance boosts trust and helps to acquire extra information; often requests for more specific information are made - I love everything you have already shared with me about yourself and I believe you can open up and tell me more about you; Do you have skype? So that we can there always to express ourselves more. The function of reconnaissance is to elicit information that would facilitate the scammer's goal to obtain financial means; for that reason, the disclosure of private information signals the victim trusts the scammer.

In the delivery stage, the scammer confirms the receipt of information $-I$ appreciate all you have said and I'm prepared to take it into my heart and perhaps 
more importantly act upon what you said. The scammer concocts an autobiography of either integrity and success or personal tragedy (features of nonstandard English have been retained for illustrative purposes) - I lost my parents when I was 12 years old and I was the only child of my parents. Unlucky I lost my uncle in 2 years after I join the military Academy and I have no family now expect my son. Am American by nationality from the Amish Pennsylvania Dutch Country Lancaster city. I was born on the 14 February 1962 at the Amish Community Hospital. The people of Amish have a strong sense of community spirit and often come to the aid of those in need. Their barn raising are a good example.

The function of delivery is to acknowledge the seriousness and importance of the received information. In acknowledging it, trust consolidates the relationship.

The final step is to employ trickery. Its function is to either obtain relevant person's data and/or money - Darling, I was able to extend my flight ticket duration and I will not need extra money to buy another ticket...I only need EUR 2,500 to settle the remaining amount to the customs and leave here for Latvia as soon as possible. If I get the money tomorrow to settle the remaining amount to the customs, I will be to depart from here to Latvia, immediately.

In the structure of online dating scams, the following objectives are implemented:

1) motivation to find an ideal partner - I call you a friend and hoping you will be more than a friend in my heart; I seek for a lady that has "twinkle in her eye", and enjoys living life to the most. She must be a woman who is not self absorbed and has a kind of heart and a positive attitude toward people and life in general; My woman should be a woman of integrity, honest, confident, kind and with a sense of humour...an intelligent woman who is able to converse on several subjects without getting into passionate arguments all the time. A woman who is very affectionate, easy going, understanding, trustworthy, family oriented and supportive. She should be fun loving and love to laugh;

2 ) to present a victim with an ideal profile and a promise of exclusivity - I enjoy going out to dinner, movies, walks and quiet times. I love nature, enjoy swimming and have a deep respect and love for children. I am fascinated with the world. I love to laugh. I have learned to take life as it comes, knowing who I am and where I am going. Engage only in relationships where both partners can openly discuss their wants and needs;

3) gauging whether the potential victim might be ready and willing to part with money - baby, are you sure you sent them the money...baby, I am dying now ... they stuck at the bank and complaining to me that I am wasting their time and joking with them, go check the number again and try and come on messenger so we talk about it;

4) persuading the potential victim to send money - Please use Western union or Money Gram to send the money to the Doctor in India. Because it is an easy and Secure method of sending money. The doctor can help me and give me the money very fast if you send it tomorrow Monday a least; 
5) consolidation of 'crisis narrative' - Unfortunately, I am stuck here in this Hospital bed awaiting proper treatments...what will happen if you come to England and meet me in a wheel chair because I have not been properly treated;

6) revictimization - Remember also that I was planning to run away from the Hospital but you told me to stay behind that you will help me with money for treatments.

In cybercrime, Whitty and Young have identified the stages of fraud (Whitty, Monica and Young 2017: 152), and they correspond to stages established in all letter-sets. Scammers use a typically uniform macrostructure with varying microlinguistic elements. Because scammers often correspond with several potential victims, the macrostructure of letters-sets tends to be quite similar from set to set. The examples show well-designed strategies of scam applied for the result of obtaining money from the victim. Fraud combines both linguistic and psychological factors, and they may work in various case scenarios. Trust is a fundamental property of interpersonal communication that can be abused and mistreated. Messages of loyalty in online romance dating are often interpreted either faithfully or with suspicion; however, a large number of financial and legal cases have been reported and filed internationally drawing attention to flawed communication known as online romance scam.

\section{Conclusions}

Online dating scam encompasses linguistic and psychological dimensions with potentially ensuing legal and financial consequences. Manipulative effects of the illusion of meaning and intention in romance scams (i.e., linguopsychological tricks of trust to extort financial assets with the help of fraudulent and premeditated e-communication between victimizer and victim) have helped to identify linguistic patterns at textual micro- and macrolevels.

It has been established that the multimodal communication presents not only opportunities but also global threats if the so-called 'red flags' are ignored or misinterpreted. The illusory nature of romance scam blurred the victim's distinction between the intent and meaning because scenarios in scam letter-sets were premeditated, structurally adjusted to prey on unsuspecting individuals' money. Both microlinguistic and macrostructural properties were uniform across scam e-letters, for example, forms of address, letter closings, objectives and functions.

After the analysis of letter-sets with the authors of the article deliberately engaging in the communication with scammers, it has been established that a superficial content with repeated lexico-textual patterns, namely, lexical and syntactical repetitions and emphases have resulted in an automatized, clichéd ecommunication. To identify romance scammers, the focus should also be on the logic of language, its non-English patterns, and manipulative incongruent 
linguistic factors such as unverifiable facts. Besides, the scammers, who engaged in the communication with the authors of the article, finally admitted themselves as nationals of Ghana who got encouragement in the success stories from Nigerian scammers.

Further, the method of structural reduction has helped to identify stages, functions and objectives in letters that positioned the victim and the scammer as participants in an interactional linguopsychological lose-or-win game. Established lnguistic and structural similarities across online dating messages may serve as templates of warning not to disclose personal information and disagree to participate in any suspicious online financial schemes disguised as dating online. Unfortunately, daters' frequent success stories are often shadowed by victims' highly negative experiences in online communication.

Currently, online dating scam is a global online threat to consenting individuals' emotional and financial well-being, and the study of scammers' elaborate linguistic and psychological devices has been a step towards a more secure online communication. Linguistic patterns, malicious intent, and detrimental mental outcomes should be, further, studied with the active participation of interdisciplinary teams internationally to increase the awareness of possible threats in global e-communication, and to ensure social media as safer platforms for mutual interaction.

\section{References}

Cappelen, Herman, Dever, Josh. 2016. Context and Communication. Oxford: Oxford University Press.

Chandler, David. 2002. Semiotics. London: Routledge.

Colman, M. Andrew. 2001. Oxford Dictionary of Psychology. Oxford: Oxford University Press.

Coulthard, Malcolm and Johnson, Alison. 2007. An Introduction to Forensic Linguistics: Language in Evidence. London, New York: Routledge. https://doi.org/10.4324/9780203969717

Deumert, Ana. 2014. Sociolinguistics and Mobile Communication. Edinburgh: Edinburgh University Press Ltd.

Hill, Graham. 2009. AS\&A Level Psychology Through Diagrams. Oxford Revision Guides. Oxford: Oxford University Press.

Janicki, Karol. 2015. Language and conflict. Selected Issues. London, New York: Macmillan Palgrave. https://doi.org/10.1007/978-1-137-38141-5

Joinson, Adam and Whitty, Monica. 2009. Truth, Lies and Trust on the Internet. London, New York: Routledge.

Joseph, E. John. 2004. Language and Identity. Houndmills, New York: Palgrave Macmillan.

Locatelli, Roberta and Wilson, A. Keith. 2017. Introduction: Perception without Representation. Topoi. [Online] Open Access 36. 197-212. Available from: http://eprints.gla.ac.uk/136311/1/136311.pdf. $\quad$ [Accessed: $5^{\text {th }}$ August 2018]. https://doi.org/10.1007/s11245-017-9460-1

Luchjenbroers, June, Olsson, John. 2014. Forensic Linguistics. London: Bloomsbury.

ONLINE R-SCAMS. 2017. Online Romance Scams Are Fleecing More Americans. [Online] Available from: https://www.forbes.com/sites/dianahembree/2017/06/20/romance-scam-crimeson-the-rise/\#187d57915ec1 [Accessed: $6^{\text {th }}$ June 2018]. 
Rege, Aunshul. 2009. What's Love Got to Do with It? Exploring Online Dating Scams and Identity Fraud. International Journal of Cyber Criminology. [Online] Open Access 3 (2). 494-512. Available from: http://www.cybercrimejournal.com/aunshulregedec2009.htm. [Accessed: $5^{\text {th }}$ August 2018].

R-SCAMS. 2018. Romance Scams Lead to Broken Hearts, Empty Bank Accounts. [Online] Available from: https://news.yahoo.com/amphtml/romance-scams-lead-broken-hearts134016523.html [Accessed: $5^{\text {th }}$ May 2018].

SCAMS. 2014. Scams of the Heart. [Online] Available from: scamsoftheheart.blogspot.com [Accessed: 10 ${ }^{\text {th }}$ June 2018].

Schaffer, Deborah. 2012. The Language of Scam Spams: Linguistic features of "Nigerian Fraud" EMails. A Review of General Semantics. Vol. 69. 157-179.

Smail, David. 2015. Illusion and Reality: The Meaning of Anxiety. Abingdon, New York: Karnac Books Ltd.

Tatar, Taner. 2018. The Illusion of Identity. International Journal of Turcologia. Vol. 13. Issue 25. [Online] Available from: https://web.b.ebscohost.com. [Accessed: $6^{\text {th }}$ August 2018].

Whitty, Monica and Young, Garry. 2017. Cyberpsychology. The Study of Individuals, Society and Digital Technologies. Oxford: The British Psychological Society. 